\title{
Druckfehlerberichtigung
}

in der Arbeit

\section{Dickdarmperforation oberhalb einer Stenose ohne Auftreibung des Darms.}

\author{
Von Dr. E. Nägelsbach.
}

(Deutsche Zeitschrift für Chirurgie, Bd. 164, S. 424-428.)

S. 424 in der Überschrift lies: E. Nägelsbach statt A. Nägelsbach.

S. 425 Zeile 16 v. oben lies: Shimodaira statt Shimodeira.

S. 425 Zeile 9 v. unten lies: Atresie statt Hernie.

S. 426 Zeile 6 v. oben lies: Kotsäule statt säule.

S. 426 Zeile 6 v. oben lies: Flexur statt Flexus.

S. 426 Zeile $9 \mathrm{v}$. unten lies: Atresie statt Atresiboe.

S. 427 unter Nr. 8 lies: Bruns' statt Bruuns'.

S. 428 unter Nr. 15 lies: Dehnungsgangrän. 